\title{
Desempenho de plantas de cobertura submetidas à déficit hídrico
}

\section{Performance of cover crop under the water deficit}

\author{
Fabiano André Petter ${ }^{1 *}$; Leandro Pereira Pacheco ${ }^{2}$; Alan Mario Zuffo \\ Adelfran Cavalcante Piauilino ${ }^{3}$; Zilmar Fernandes Xavier ${ }^{3}$; \\ Jodson Moraes dos Santos ${ }^{3}$; João Marcos de Souza Miranda ${ }^{3}$
}

\section{Resumo}

Objetivou-se com esse trabalho avaliar o efeito do déficit hídrico na produção de fitomassa de diferentes plantas de cobertura. O experimento foi conduzido em casa de vegetação, na área experimental do campus da Universidade Federal do Piauí (UFPI), em solo classificado como Latossolo Amarelo distrófico. Os tratamentos foram compostos pela combinação cinco espécies de plantas de cobertura (Brachiaria brizantha cv. Xarés; Pennisetum glaucum cv. ADR 300; Brachiaria ruziziensis; Mucuna aterrima; Pennisetum. glaucum cv. ADR 7010) e quatro intervalos de turno rega (2, 4, 6 e 8 dias). Independente dos níveis de déficit hídrico, as maiores produções de fitomassa foram obtidas nas espécies de B. brizantha, B. ruziziensis, P. Glaucum cv. ADR 300 e ADR 7010. Observou-se maior tolerância de $M$. aterrima aos níveis de déficit hídrico. As espécies de B. brizantha e B. ruziziensis acumularam $70 \%$ da fitomassa da parte aérea nas folhas, enquanto que, P. glaucum cv. ADR 300 e ADR 7010 acumularam $60 \%$ no caule. Mesmo com reduções da fitomassa em condições de déficit hídrico, as espécies de $B$. brizantha e B. ruziziensis apresentam potencial para cobertura do solo e o P. glaucum como fonte de resíduos para manutenção da matéria orgânica do solo.

Palavras-chave: Plantio direto, Pennisetum glaucum, Brachiaria sp., Mucuna aterrima, umidade do solo

\begin{abstract}
The objective of this study was to evaluate the effect of drought on biomass of different cover crops. The experiment was conducted in a greenhouse at the experimental campus of the Federal University of Piauí (UFPI), on soil classified as Yellow Latosol dystrophic. The treatments were composed by five species of cover crops (Brachiaria brizantha cult. Xarés; Pennisetum glaucum cv. ADR 300; Brachiaria ruziziensis; Mucuna aterrima; Pennisetum. glaucum cv. ADR 7010) and four irrigation intervals levels (2, 46 and 8 days). Independent of the levels of water deficit, the highest biomass were obtained in species B. brizantha, B. ruziziensis, P. Glaucum cv. ADR 300 and ADR 7010. There was greater tolerance of $M$. aterrima levels of water deficit. The species of B. brizantha and B. ruziziensis accumulated $70 \%$ of the dry weight of tops of sheets, while P. glaucum cv. ADR 300 and ADR 7010 accumulated $60 \%$ of the stem. Even with reductions in biomass under water deficit conditions, the species B. brizantha and B. ruziziensis have potential for soil cover and P. glaucum residues as a source for the maintenance of soil organic matter.
\end{abstract}

Key words: Direct drill, Pennisetum glaucum, Brachiaria sp., Mucuna aterrima, soil moisture

\footnotetext{
${ }^{1}$ Prof. Adjunto do Dept ${ }^{\circ}$ de Agronomia, Fitotecnia, Universidade Federal de Mato Groso, UFMT, Sinop, MT. E-mail: petter@ufmt.br

${ }^{2}$ Prof. Adjunto do Dept $^{\circ}$ de Engenharia Agrícola, UFMT, Rondonópolis, MT. E-mail: leandroppacheco@gmail.com

${ }^{3}$ Discentes de Mestrado do Programa de Pós-Graduação em Agronomia, Fitotecnia, Universidade Federal do Piauí, UFPI, Piauí, PI. E-mail: zuffo@ufpi.edu.br; acpiaulino@yahoo.com.br; zilmarfxavier@hotmail.com; jodsonmsantos@hotmail.com; jmarcosmiranda@bol.com.br

* Autor para correspondência
} 


\section{Introdução}

O Cerrado brasileiro se destaca no cenário agrícola. É responsável por boa parte da área agricultável no País. Nessa região predomina como culturas demandantes a soja, o arroz de terras altas, o algodão e o milho. Devido o crescimento populacional, aumentou-se a demanda por alimentos e, consequentemente, as áreas cultivadas com essas culturas.

Nesse Bioma, o crescimento da área agricultável, frequentemente, ocorre em áreas de reserva e preservação (PETTER; MADARI, 2012). A derrubada e queima da mata ocasiona perda da fertilidade natural do solo, redução da matéria orgânica do solo (MOS) e liberação de dióxido de carbono $\left(\mathrm{CO}_{2}\right)$ e outros gases de efeito estufa (GEE) para a atmosfera (MACHADO, 2005). Extensas áreas de pastagens degradadas poderiam ser utilizadas para o fim de se produzir alimentos, contudo devido à baixa fertilidade desses solos, os produtores preferem abrir novas áreas.

Nos solos de cerrado, como os Latossolos, Neossolos, Argissolos, na maioria das vezes a fertilidade restringe-se a camada superficial do solo e a perda de matéria orgânica (MO) dessa camada reduz o potencial produtivo desses solos. Segundo estimativas, a MOS tem três vezes mais carbono do que a existente em toda a biomassa vegetal terrestre (BATJES, 1996) e as emissões de $\mathrm{CO}_{2}$ do solo, pela ação antrópica, somam aproximadamente $25 \%$ das emissões do $\mathrm{CO}_{2}$ do planeta (BOUWMANN; GERMON, 1998). Entretanto, no Bioma Cerrado a taxa de mineralização da MO atinge altos níveis na decomposição desses resíduos, em razão da elevada temperatura e atividade microbiológica, reduzindo a quantidade desses compostos no solo (TORRES et al., 2005).

Diante disso, a incorporação de $\mathrm{MO}$ e a manutenção dos seus níveis no solo contribuem para a fixação de carbono e redução do efeito estufa e, não menos importante, para a manutenção da fertilidade. De acordo com Pacheco e Petter (2011), a matéria orgânica é de grande importância para as propriedades químicas e físicas dos solos de cerrado, contribuindo em até $80 \%$ da capacidade de troca catiônica (CTC) do solo. Através do uso de plantas de cobertura, a adoção do sistema de plantio direto (SPD) tem proporcionado a manutenção dos estoques de carbono no solo (PRIOR et al., 2004) e consequentemente melhorando os atributos químicos (HEINRICHS et al., 2005), físicos (MOREIRA et al., 2009) e biológicos do solo (SILVA et al., 2007).

O SPD tem seu alicerce em três requisitos mínimos: não revolvimento do solo, rotação de culturas e manutenção de restos vegetais na superfície do solo. Todavia, em função da distribuição irregular e limitação na disponibilidade hídrica no cerrado (ex. cerrado piauiense), o estabelecimento de espécies visando à manutenção de palhada principalmente na entressafra, tem sido entrave em algumas regiões (PACHECO et al., 2008), onde em função dessa dificuldade, predomina o sistema de cultivo de semeadura direta e não o SPD. Diante disso, tem se buscado o cultivo de espécies que apresentam elevada capacidade de produção de fitomassa seca em condições de déficit hídrico e que apresentam boa resistência à decomposição na entressafra (GIACOMINI et al., 2003; CRUSCIOL et al., 2005).

Algumas espécies tem se destacado como plantas de cobertura na região dos cerrados, como é o caso do Pennisetum glaucum (milheto), que tem sido apontada (BOER et al., 2007; TORRES, PEREIRA, FABIAN, 2008) como espécie de elevada produção de fitomassa na entressafra. No entanto, essa produção de fitomassa é altamente dependente da disponibilidade hídrica, como verificado por Sodré Filho et al. (2004). De acordo com Pacheco et al. (2011b), o uso de espécies perenes, como Brachiaria brizantha e Brachiaria ruziziensis, também tem sido difundido por apresentarem boa tolerância ao déficit hídrico. Essas espécies apresentam comportamento diferenciado quanto ao desenvolvimento na entressafra. A produção de fitomassa das Brachiaria 
é menor nos períodos iniciais da safrinha quando comparado ao milheto, todavia, após o início das primeiras chuvas (setembro-outubro) a capacidade de rebrota é alta, proporcionando significativos acúmulos de fitomassa (PACHECO et al., 2011a). A capacidade de rebrota está associada à boa formação do sistema radicular. É uma importante característica, que segundo Sodré Filho et al. (2004), faz com que espécies como a mucuna preta (Mucuna aterrima) também seja recomendada como planta de cobertura na entressafra na região dos cerrados.

Considerando a importância exercida pelas plantas de cobertura no SPD, que ganha destaque à medida que os efeitos de uma agricultura extrativista e predatória se intensificaram, a necessidade de implementação desse sistema em regiões onde se utiliza apenas a semeadura direta e diante da distribuição irregular e limitada da disponibilidade hídrica de algumas regiões no cerrado, estudos que visam à adaptação de espécies como plantas de cobertura em condições de baixa precipitação, devem ser realizados.
Portanto, este trabalho teve por objetivo verificar o desempenho agronômico de plantas de cobertura submetidas ao déficit hídrico na região do cerrado piauiense.

\section{Material e Métodos}

O experimento foi conduzido em casa de vegetação, na área experimental do campus da Universidade Federal do Piauí (UFPI) em Bom

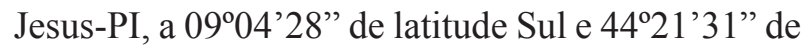
longitude Oeste e com altitude média de $277 \mathrm{~m}$, no período de Junho a Agosto de 2011.

O clima da região é do tipo Aw segundo a classificação climática global de Köppen, com duas estações bem definidas. Uma seca que vai de maio a setembro e outra chuvosa que vai de outubro a abril. Os dados climáticos foram coletados na estação meteorológica do Instituto Nacional de Meteorologia - INMET a aproximadamente 200 metros do local de condução do experimento e encontram-se na Figura 1.

Figura 1. Temperatura média, umidade relativa do ar e insolação, durante a condução do experimento (dados do INMET - estação de Bom Jesus-PI).

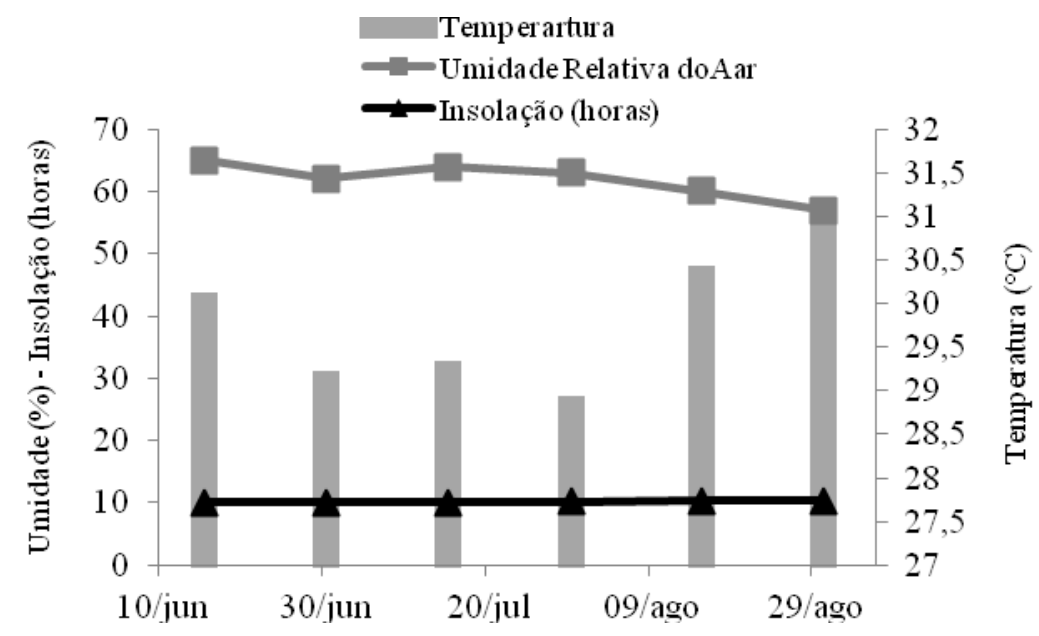

Fonte: Elaboração dos autores. 
O solo utilizado no experimento foi coletado em área de produção de soja, na camada de 0 a $20 \mathrm{~cm}$, classificado como Latossolo Amarelo distrófico, apresentando as seguintes características físicas e químicas: 762, 57 e $181 \mathrm{~g} \mathrm{~kg}^{-1}$ de areia, silte e argila, respectivamente; $\mathrm{P}-23,7 \mathrm{mg} \mathrm{dm}^{-3} ; \mathrm{K}-34,0 \mathrm{mg} \mathrm{dm}^{-}$ 3; $\mathrm{Ca}-2,0 \mathrm{cmol}_{\mathrm{c}} \mathrm{dm}^{-3} ; \mathrm{Mg}-0,7 \mathrm{cmol}_{\mathrm{c}} \mathrm{dm}^{-3} ; \mathrm{H}-4,5$ $\mathrm{cmol}_{\mathrm{c}} \mathrm{dm}^{-3}$; $\mathrm{Al}-0,3 \mathrm{cmol}_{\mathrm{c}} \mathrm{dm}^{-3}$; M.O. $-16,2 \mathrm{~g} \mathrm{dm}^{-3}$; CTC $-7,4 \mathrm{cmol}_{\mathrm{c}} \mathrm{dm}^{-3}$.

$\mathrm{O}$ delineamento experimental utilizado foi $\mathrm{em}$ blocos casualizados, em esquema fatorial $5 \times 4$, sendo os fatores constituídos por cinco diferentes espécies de plantas de cobertura (Brachiaria brizantha cv. Xaraés; Pennisetum glaucum cv. ADR 300; Brachiaria ruziziensis; Mucuna aterrima; Penisetum glaucum cv. ADR 7010) e quatro intervalos de turno de rega $(2,4,6$ e 8 dias) correspondente a $80 \%, 60 \%, 40 \%$ e $20 \%$ da capacidade de campo, com quatro repetições.

Asemeadura das plantas de cobertura foi realizada no dia 11 de junho de 2011, com dez sementes por vaso $\left(8 \mathrm{dm}^{-3}\right)$ e aos 15 dias após a emergência das plantas foi realizado desbaste deixando-se duas plantas por vaso. A adubação foi equivalente a $3 \mathrm{~g}$ do formulado NPK (5-30-15) em cada vaso. Aos 20 dias após plantio (DAP) foi realizada adubação de cobertura, acrescentando $3 \mathrm{~g}$ da formulação NPK (530-15) por vaso.

Os intervalos de turno de rega foram determinados da seguinte forma: a) determinou-se a massa dos vasos na capacidade de campo por meio de metodologia adaptada de Bonfim-Silva et al. (2011) e Cavalcante et al. (2011), no qual saturou-se os vasos com água, deixando-os em repouso por 12 horas para escorrer a água em excesso e determinar a massa; b) em seguida, aplicou-se os tratamentos com intervalos de déficit hídrico (2, 4, 6 e 8 dias), no qual, a cada intervalo adicionou-se a quantidade de água para completar a capacidade de campo, por meio da diferença de massa calculada do vaso no estado de capacidade de campo e da massa atual do vaso. Em todos os tratamentos foi mantido o solo com umidade de $70-80 \%$ da capacidade de campo até os 30 dias após emergência (DAE), visando simular as chuvas finais de verão e promover o estabelecimento inicial das plantas. Após este período foram aplicados os diferentes níveis de déficit hídrico.

Aos 65 DAE foram avaliados as características biométricas: número de folhas, de forma manual selecionando apenas uma planta por vaso, altura de planta, com o auxílio de trena graduada em metro, medida do colo até o ápice, comprimento do caule com distância entre o colo e o ponto de inserção da folha mais jovem com o auxílio de uma trena graduada, diâmetro do caule utilizando paquímetro digital graduado em milímetro. O teor de clorofila foi avaliado com uso de clorofilômetro modelo "ClorofiLog-CFL1030", para o qual foi escolhida duas folhas adultas por planta e realizada a leitura de 3 pontos em diferentes partes na mesma folha. $\mathrm{O}$ volume radicular foi avaliado segundo metodologia descrita por Cavalcante et al. (2011), no qual a raiz foi lavada e deixada por um período de secagem a sombra para retirada do excesso de água. Em seguida colocou-se na proveta de $1 \mathrm{~L}$, valor padrão de água, cerca de $300 \mathrm{~mL}$, no qual foram emergidas as raízes calculando-se o volume radicular pela diferença de volume de água deslocada na proveta. Realizou-se também a fitomassa seca oriunda das folhas verdes e secas, fitomassa seca do colmo, raízes e total, com auxilio de estufa de circulação de ar forçado, a $65^{\circ} \mathrm{C}$, por 72 horas, até obtenção de massa constante, e, em seguida pesou-se os resíduos vegetais de forma separada.

Os dados avaliados foram submetidos à análise de variância e as médias das variáveis significativas comparadas pelo teste Tukey (5\%), utilizando-se o programa estatístico Sisvar 4.1. Já para a análise dos fatores quantitativos, utilizou-se da regressão linear e polinomial para auxiliar na escolha do modelo que se ajustasse aos dados para cada espécie de planta de cobertura, bem como os valores do coeficiente de determinação associado a cada modelo de regressão. A significância dos parâmetros das 
equações foi determinada utilizando-se o teste " $t$ " de Student a 5\% de probabilidade, utilizando o software SigmaPlot.

\section{Resultados e Discussão}

O maior número de folhas foi verificado para M. aterrima e B. ruziziensis (Figura 2). Com exceção de $M$. aterrima, em que, para o número de folhas a equação se ajustou de maneira quadrática, evidenciando maior tolerância dessa espécie em condições intermediárias de umidade no solo, as demais espécies de plantas apresentaram redução linear no número de folhas com o aumento da intensidade do déficit hídrico. Por ser leguminosa e que não há perfilhamento, em $M$. aterrima, a produção de fotoassimilados é direcionada para o crescimento apical, resultando em maior crescimento do caule (Figura 3A), em altura (Figura 3B) e número de folhas.

Figura 2. Número de folhas (A) e diâmetro do caule (B) de plantas de cobertura em função do intervalo de turno de rega (déficit hídrico). ns não significativo; ${ }^{*} \mathrm{e}^{*}$ significativo a $1 \%$ e $5 \%$ de probabilidade respectivamente pelo teste " $\mathrm{t}$ " de Student.

(A)

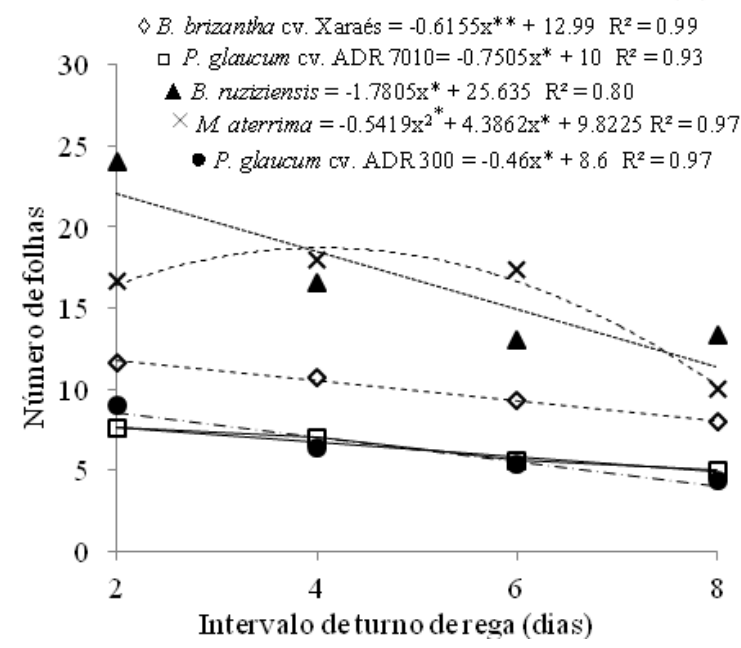

Fonte: Elaboração dos autores.

Apesar de maior número de folhas, maior crescimento do caule e altura de plantas, o acúmulo de fitomassa seca em M. aterrima foi significativamente menor comparado às demais espécies (Tabela 1). Em contrapartida ao crescimento em parte aérea (altura), a $M$. aterrima apresenta em seus estágios iniciais de crescimento, menor acúmulo de fitomassa e volume do sistema radicular (Tabela 1), caracterizando partição diferenciada de fotoassimilados comparado às demais espécies avaliadas. Essa característica pode ser desfavorável como planta de cobertura

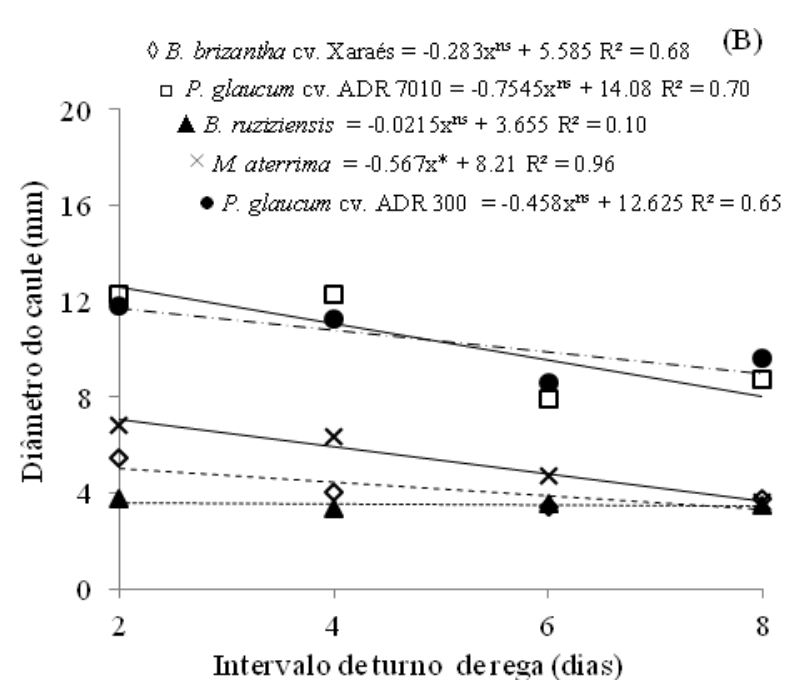

na entressafra, principalmente em regiões que não ocorre precipitação durante esse período, ou que, a disponibilidade hídrica é irregular e limitada, que é o caso do cerrado Nordestino. Outro fator importante a ser considerado é o diâmetro do caule de $M$. aterrima, que apesar de apresentar maior comprimento, não apresenta maior diâmetro, o que pode contribuir para maior acamamento e aumento da taxa de decomposição dos resíduos. Os maiores diâmetros do caule foram verificados em $P$. galucum cv. ADR 300 e 7010. 
Figura 3. Comprimento do caule (A) e altura (B) de plantas de cobertura em função do intervalo de turno de rega (déficit hídrico). ${ }^{n s}$ não significativo; $* *$ e $*$ significativo a $1 \%$ e $5 \%$ de probabilidade respectivamente pelo teste " $\mathrm{t}$ " de Student.
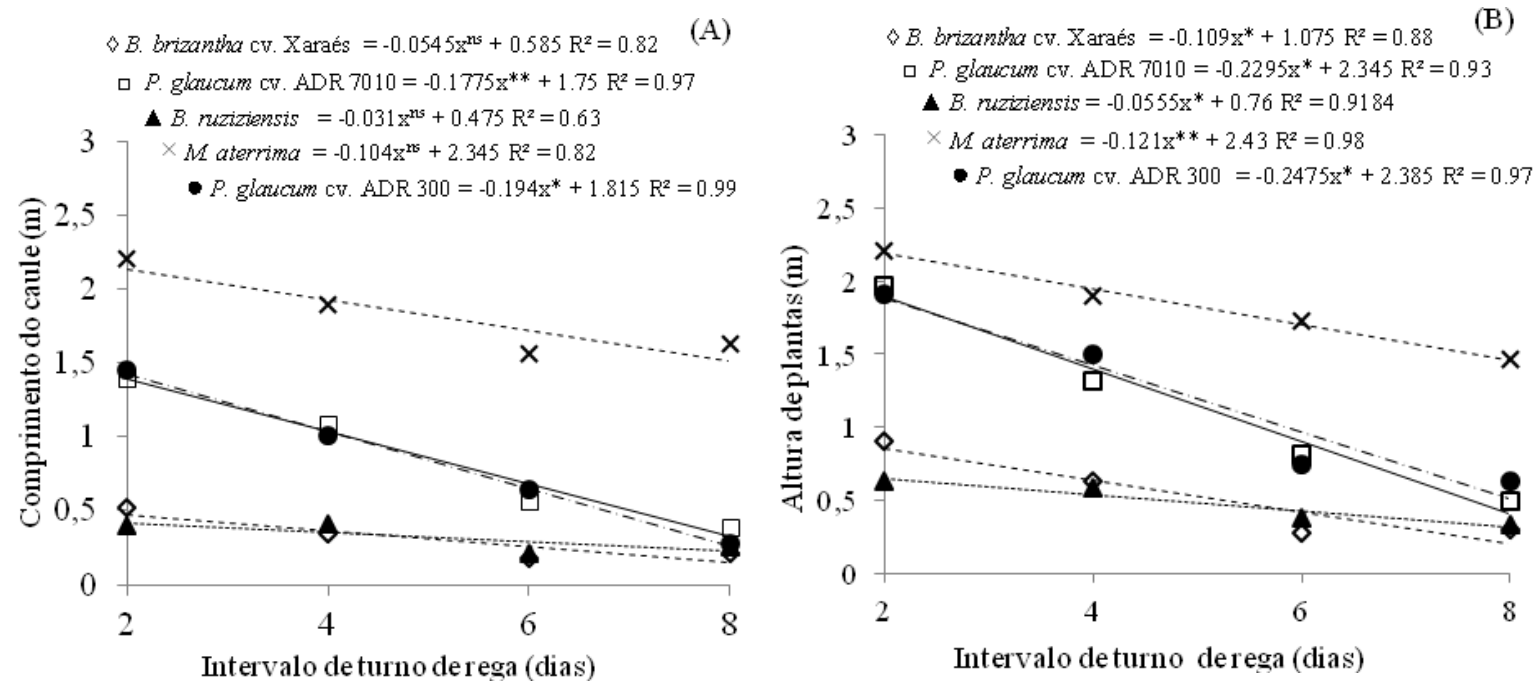

Fonte: Elaboração dos autores.

Tabela 1. Fitomassa seca de folhas verdes e secas, do caule, raízes e fitomassa seca total das plantas de cobertura submetidas a quatro intervalos de turno de rega.

\begin{tabular}{|c|c|c|c|c|c|}
\hline \multirow{3}{*}{ Plantas de cobertura } & \multicolumn{5}{|c|}{ Intervalos de turno de rega } \\
\hline & 2 & 4 & 6 & 8 & Média \\
\hline & \multicolumn{5}{|c|}{ Fitomassa seca de folhas secas - FSFS (g 2 plantas $\left.^{-1}\right)$} \\
\hline B. brizantha cv. Xaraés & $4,50 \mathrm{BC}$ & $8,70 \mathrm{BC}$ & $12,33 \mathrm{~A}$ & $10,00 \mathrm{~A}$ & $8,90 \mathrm{~A}$ \\
\hline P. glaucum cv. ADR 300 & $7,90 \mathrm{AB}$ & $11,86 \mathrm{AB}$ & $9,93 \mathrm{~A}$ & $10,00 \mathrm{~A}$ & $9,92 \mathrm{~A}$ \\
\hline B. ruziziensis & $6,10 \mathrm{~B}$ & $6,96 \mathrm{C}$ & $9,90 \mathrm{~A}$ & $11,93 \mathrm{~A}$ & $8,72 \mathrm{~A}$ \\
\hline M. aterrima & $2,20 \mathrm{C}$ & $2,33 \mathrm{D}$ & $1,03 \mathrm{~B}$ & $0,50 \mathrm{~B}$ & $1,51 \mathrm{~B}$ \\
\hline \multirow[t]{2}{*}{ P. glaucum cv. ADR 7010} & $10,10 \mathrm{~A}$ & $13,80 \mathrm{~A}$ & $8,66 \mathrm{~A}$ & $8,26 \mathrm{~A}$ & $10,20 \mathrm{~A}$ \\
\hline & \multicolumn{5}{|c|}{ Fitomassa seca de folhas verdes - FSFV (g 2 plantas $^{-1}$ ) } \\
\hline B. brizantha cv. Xaraés & $37,30 \mathrm{~A}$ & $21,90 \mathrm{~A}$ & $5,43 \mathrm{~B}$ & $3,36 \mathrm{~A}$ & $17,00 \mathrm{~A}$ \\
\hline P. glaucum cv. ADR 300 & $21,23 \mathrm{~B}$ & $9,73 \mathrm{~B}$ & $6,93 \mathrm{AB}$ & $6,00 \mathrm{~A}$ & $10,97 \mathrm{~B}$ \\
\hline B. ruziziensis & $31,16 \mathrm{~A}$ & $20,73 \mathrm{~A}$ & $13,43 \mathrm{~A}$ & $4,33 \mathrm{~A}$ & $17,41 \mathrm{~A}$ \\
\hline M. aterrima & $11,33 \mathrm{C}$ & $13,53 \mathrm{~B}$ & $7,43 \mathrm{AB}$ & $7,23 \mathrm{~A}$ & $9,88 \mathrm{~B}$ \\
\hline P. glaucum cv. ADR 7010 & $9,36 \mathrm{C}$ & $9,63 \mathrm{~B}$ & $8,03 \mathrm{AB}$ & $4,86 \mathrm{~A}$ & $7,97 \mathrm{~B}$ \\
\hline \multicolumn{6}{|c|}{ Fitomassa seca do caule - FSC (g 2 plantas $\left.^{-1}\right)$} \\
\hline B. brizantha cv. Xaraés & $34,23 \mathrm{C}$ & $22,60 \mathrm{C}$ & $10,30 \mathrm{AB}$ & $5,66 \mathrm{~A}$ & $18,20 \mathrm{C}$ \\
\hline P. glaucum cv. ADR 300 & $77,43 \mathrm{~A}$ & $33,26 \mathrm{AB}$ & $14,60 \mathrm{~A}$ & $8,26 \mathrm{~A}$ & $33,39 \mathrm{~A}$ \\
\hline B. ruziziensis & $61,70 \mathrm{~B}$ & $25,83 \mathrm{BC}$ & $12,36 \mathrm{AB}$ & $8,73 \mathrm{~A}$ & $27,15 \mathrm{~B}$ \\
\hline M. aterrima & $8,76 \mathrm{D}$ & $9,56 \mathrm{D}$ & $4,70 \mathrm{~B}$ & $3,40 \mathrm{~A}$ & $6,60 \mathrm{D}$ \\
\hline P. glaucum cv. ADR 7010 & $61,76 \mathrm{~B}$ & $35,56 \mathrm{~A}$ & $13,86 \mathrm{AB}$ & $8,83 \mathrm{~A}$ & $30,00 \mathrm{AB}$ \\
\hline
\end{tabular}

continua 
continuação

\begin{tabular}{lccccc}
\hline & \multicolumn{5}{l}{ Fitomassa seca de raízes - FSR (g 2 plantas $\left.{ }^{-1}\right)$} \\
\cline { 2 - 6 } B. brizantha cv. Xaraés & $41,03 \mathrm{AB}$ & $26,36 \mathrm{AB}$ & $11,53 \mathrm{AB}$ & $20,70 \mathrm{~A}$ & $24,90 \mathrm{~A}$ \\
P. glaucum cv. ADR 300 & $56,53 \mathrm{~A}$ & $27,96 \mathrm{AB}$ & $21,56 \mathrm{~A}$ & $14,13 \mathrm{AB}$ & $30,05 \mathrm{~A}$ \\
B. ruziziensis & $50,56 \mathrm{~A}$ & $28,16 \mathrm{AB}$ & $19,83 \mathrm{~A}$ & $7,93 \mathrm{~B}$ & $26,62 \mathrm{~A}$ \\
M. aterrima & $23,06 \mathrm{~B}$ & $10,70 \mathrm{~B}$ & $6,93 \mathrm{~B}$ & $6,26 \mathrm{~B}$ & $11,74 \mathrm{~B}$ \\
P. glaucum cv. ADR 7010 & $51,70 \mathrm{~A}$ & $39,90 \mathrm{~A}$ & $15,33 \mathrm{AB}$ & $8,16 \mathrm{~B}$ & $28,77 \mathrm{~A}$ \\
\hline & \multicolumn{5}{c}{ Fitomassa seca total - FST $\left(\mathrm{g} 2\right.$ plantas $\left.^{-1}\right)$} \\
B. brizantha cv. Xaraés & $117,06 \mathrm{~B}$ & $94,96 \mathrm{~A}$ & $56,06 \mathrm{~A}$ & $41,79 \mathrm{~A}$ & $77,46 \mathrm{~A}$ \\
P. glaucum cv. ADR 300 & $163,09 \mathrm{~A}$ & $94,31 \mathrm{~A}$ & $55,82 \mathrm{~A}$ & $39,32 \mathrm{~A}$ & $88,13 \mathrm{~A}$ \\
B. ruziziensis & $149,52 \mathrm{AB}$ & $92,11 \mathrm{~A}$ & $62,82 \mathrm{~A}$ & $42,02 \mathrm{~A}$ & $86,61 \mathrm{~A}$ \\
M. aterrima & $45,35 \mathrm{C}$ & $33,92 \mathrm{~B}$ & $26,19 \mathrm{~B}$ & $17,59 \mathrm{C}$ & $30,76 \mathrm{~B}$ \\
P. glaucum cv. ADR 7010 & $132,92 \mathrm{AB}$ & $98,62 \mathrm{~A}$ & $47,48 \mathrm{~A}$ & $33,28 \mathrm{~B}$ & $78,07 \mathrm{~A}$ \\
\hline
\end{tabular}

Médias seguidas de letras iguais nas colunas não diferem entre si de forma significativa pelo teste Tukey a $5 \%$.

Fonte: Elaboração dos autores.

De maneira geral a produção de fitomassa seca foi significativamente variável entre as espécies e significativamente influenciada pelos diferentes intervalos de turno de rega (Tabela $1 \mathrm{e}$ Figuras 4, 5A e 6). Avaliando as frações vegetais separadamente, a média de produção de fitomassa seca oriunda de folhas secas, verdes, caule, raízes e total, independente do turno de rega, foi significativamente inferior para $M$. aterrima. Esses resultados corroboram os obtidos por Suzuki et al. (2008), que verificaram produção de fitomassa de M. aterrima, inferior a P. glaucum. Considerando a proporção de fitomassa oriunda de folhas secas, verificou-se que $M$. aterrima apresentou os menores valores, com apenas $13 \%$ da fitomassa das folhas originada das folhas secas, indicando uma maior capacidade de manutenção de folhas turgidas em condições de déficit hídrico (Figura 3).

Por outro lado, o P. glaucum cv. ADR 300 e ADR 7010 apresentaram as maiores proporções de fitomassa oriundo de folhas secas, com $47 \%$ e $56 \%$ respectivamente. A maior presença de folhas secas em P. glaucum no momento da avaliação (65 DAE) está relacionada ao ciclo dos cultivares, que já se encontravam em fase reprodutiva, o que favoreceu a translocação de fotoassimilados das folhas para as panículas.

Enquanto que, B. brizantha cv. Xaraés e $B$. ruziziensis produziram maiores quantidades de fitomassa nas folhas, P. glaucum cv. ADR 300 e ADR 7010 acumularam maiores quantidades no caule. Esses resultados atestam a maior eficiência das Brachiaria no atributo cobertura do solo, como verificado por Timossi, Durigan e Leite (2007), ao passo que $P$. glaucum pode ser mais eficiente na manutenção da permanência dos resíduos no solo. Aproximadamente $40 \%$ da fitomassa acumulada em $P$. glaucum, se encontra no caule, que são tecidos mais lignificados e com maior ralação $\mathrm{C} / \mathrm{N}$ comparados às folhas, como verificado por Sodré Filho et al. (2004), o que favorece a menor taxa de decomposição, podendo assim contribuir para a maior permanência desses resíduos na entressafra. Torres e Pereira (2008) e Pacheco et al. (2011b) verificaram tempo de meia vida dos resíduos de $P$. americanum e P. glaucum respectivamente, superiores comparado à de espécies de Brachiaria e Crotalaria. 
Figura 4. Fitomassa fresca (A) e seca (B) de folhas de plantas de cobertura em função do intervalo de turno de rega (déficit hídrico). ${ }^{n s}$ não significativo; $* *$ e $*$ significativo a $1 \%$ e $5 \%$ de probabilidade respectivamente pelo teste " $\mathrm{t}$ " de Student.
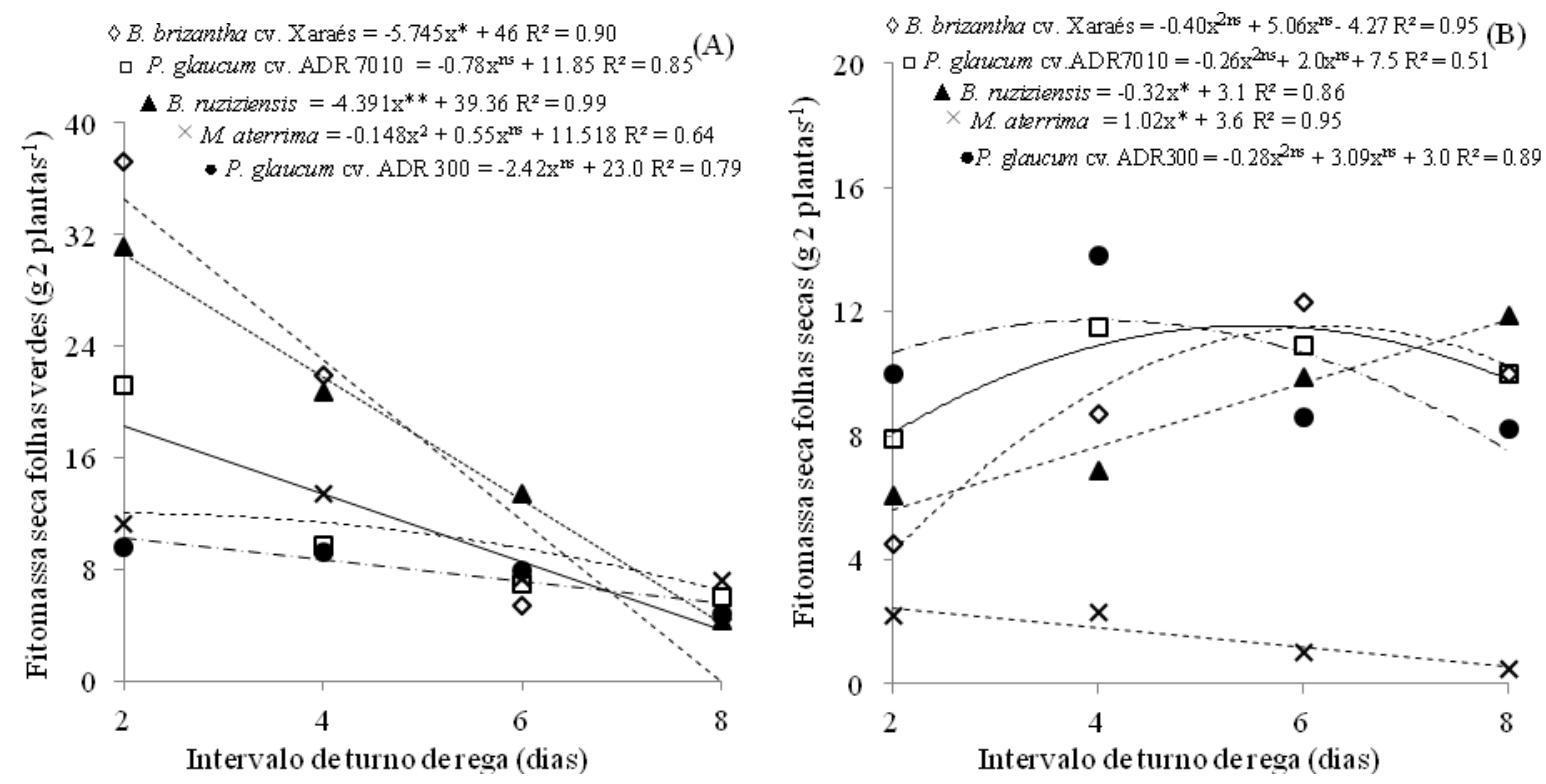

Fonte: Elaboração dos autores.

Figura 5. Fitomassa seca (A) e volume (B) de raízes de plantas de cobertura em função do intervalo de turno de rega (déficit hídrico). ${ }^{\text {ns }}$ não significativo; $* *$ e $*$ significativo a $1 \%$ e $5 \%$ de probabilidade respectivamente pelo teste "t" de Student.
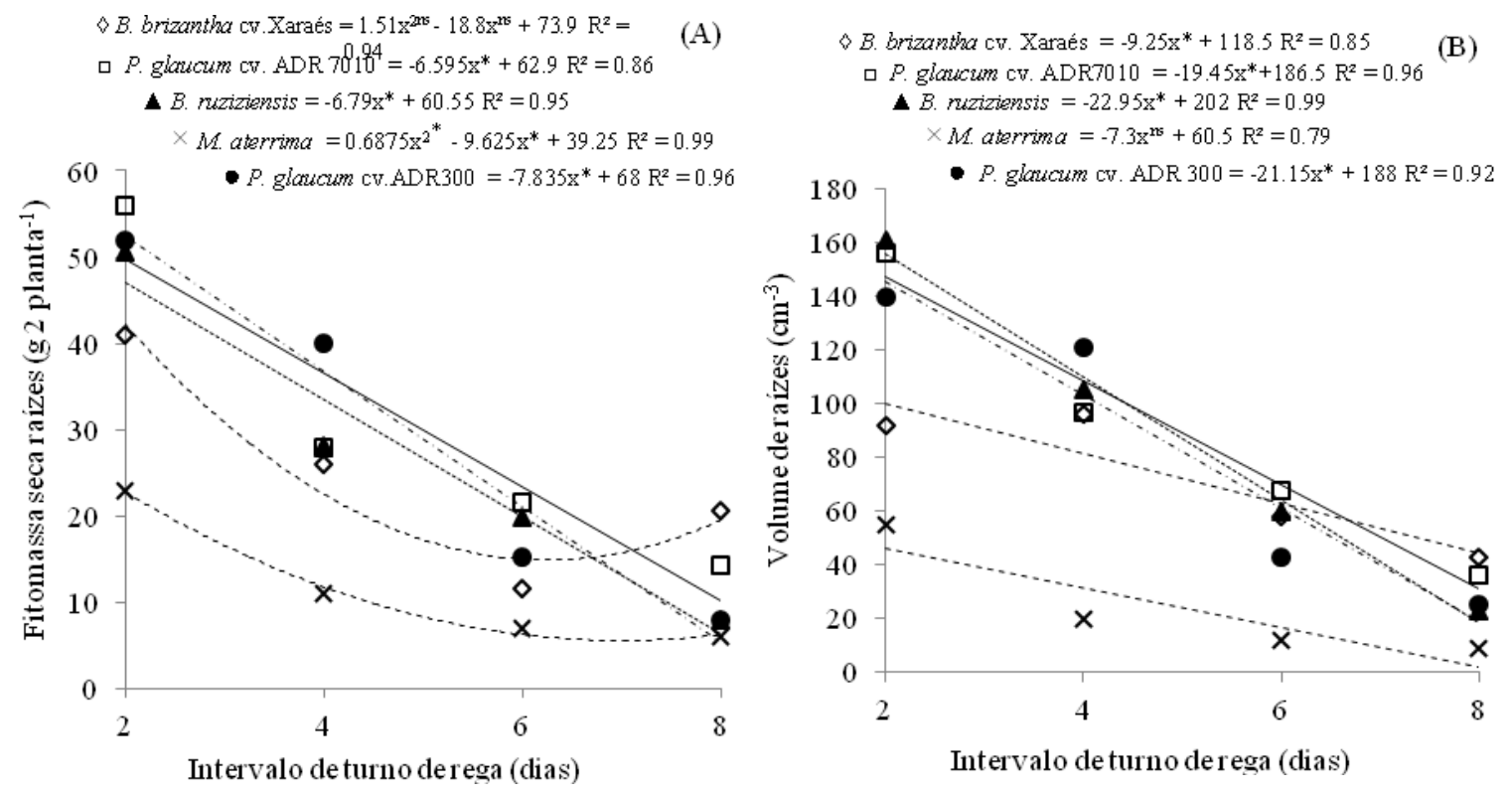

Fonte: Elaboração dos autores. 
Figura 6. Fitomassa seca do caule (A) e total (B) de plantas de cobertura em função do intervalo de turno de rega (déficit hídrico). *significativo a 1\% de probabilidade pelo teste " $t$ " de Student.

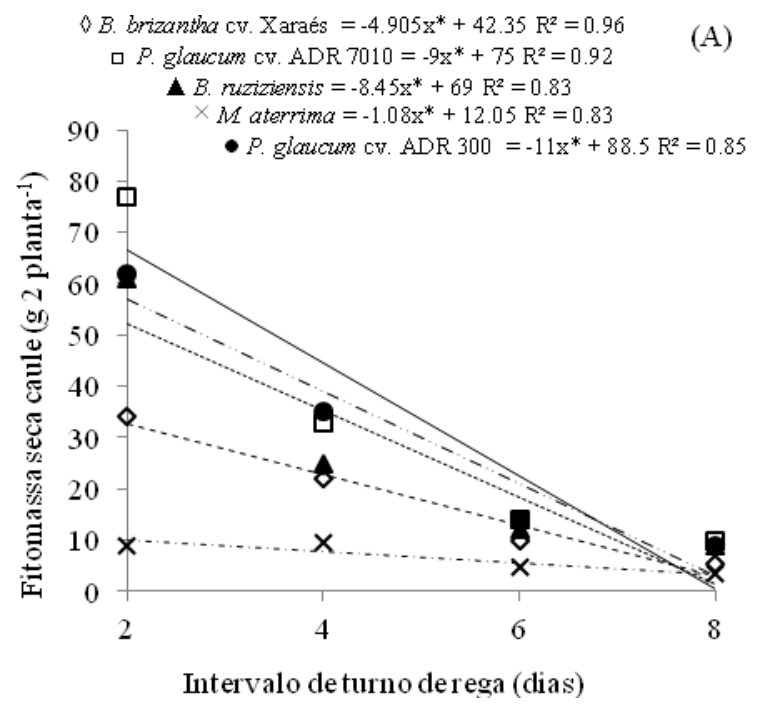

Fonte: Elaboração dos autores.

Com exceção de $M$. aterrima, que apresentou os menores valores de fitomassa seca de raízes, as demais plantas de cobertura acumularam de $30 \%$ a $36 \%$ da fitomassa seca total nas raízes (Tabela 1). Essa característica pode contribuir para uma maior tolerância dessas espécies em condições de déficit hídrico, que é característico na região dos cerrados na época da entressafra. Todavia as espécies de Brachiaria sp. apresentaram expressivas reduções no acúmulo de fitomassa seca de folhas verdes com o aumento do déficit hídrico, ao passo, que houve aumento na fitomassa seca de folhas secas (Figura 4) nos intervalos de turno de rega de 4 e 6 dias. Essa maior quantidade de folhas secas (65 DAE) com o aumento do déficit hídrico, explica parcialmente a redução da fitomassa seca total (Figura 6B) e baixa capacidade de crescimento dessas espécies na entressafra, como verificado por Pacheco et al. (2011b). Tal fato pode ser atribuído à incapacidade fotossintética dos tecidos secos. Segundo Taiz e Zeiger (2009), tecido celular não turgido tem sua capacidade fotossintética significativamente reduzida. Outro fato a ser atribuído, é o lento crescimento inicial dessas espécies, que segundo

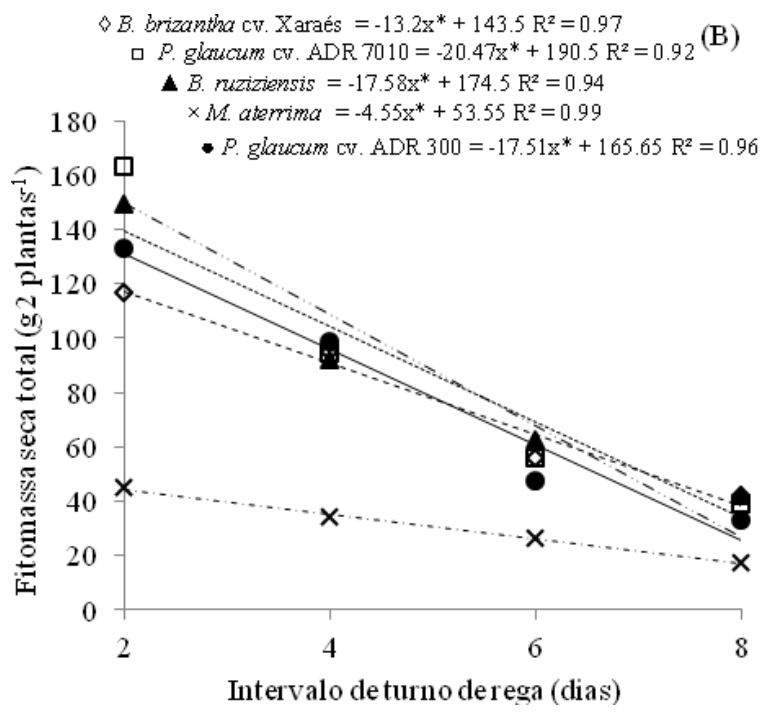

Portes et al. (2000) é mais intenso a partir do 45 DAE, período este, que geralmente coincide com o início do período de déficit hídrico na região dos cerrados, caso essas plantas de cobertura sejam semeadas em sobressemeadura ou pós-colheita.

As maiores reduções no acúmulo de fitomassa seca das raízes com o aumento dos níveis de déficit hídrico foram verificadas em $P$. glaucum cv. ADR 300 e 7010 e $B$. ruziziensis, enquanto que $M$. aterrima foi a espécie que apresentou a maior tolerância aos níveis de déficit hídrico (Figura 5A). Com exceção de $M$. aterrima, o volume do sistema radicular das demais espécies foi significativamente influenciado pelo aumento dos níveis de déficit hídrico, em que as equações se ajustaram de maneira linear (Figura 5B). No entanto, apesar de B. brizantha, $B$. ruziziensis e $P$. glaucum cv. ADR 300 e 7010, terem o volume do sistema radicular significativamente reduzido em função dos níveis de déficit hídrico, essas espécies apresentam maior volume do sistema radicular comparado à $M$. aterrima. O maior volume do sistema radicular dessas espécies pode contribuir para a redução na formação de camadas 
compactadas, proporcionar maior estabilidade de agregados, melhor infiltração da água e maior atividade dos microrganismos no solo, contribuindo para a melhoria das características químicas, físicas e biológicas do solo, como verificado Heinrichs et al. (2005), Moreira et al. (2009) e Silva et al. (2007) respectivamente.

Por serem consideradas plantas perenes, as espécies de $B$. brizantha e $B$. ruziziensis levam desvantagens no acúmulo de fitomassa seca na parte aérea durante a entressafra, comparado à $P$. glaucum, uma vez que nos estágios iniciais de desenvolvimento essas espécies direcionam boa parte dos fotoassimilados para o crescimento do sistema radicular. No entanto, essa partição diferenciada de fotoassimilados, pode favorecer a rebrota no início do período chuvoso, aumentando a capacidade de produção de fitomassa para o início do plantio de verão. Timossi, Durigan e Leite (2007) observaram elevado acúmulo de fitomassa de Brachiaria ruziziensis após as chuvas iniciais de verão, enquanto que, Boer et al. (2007) e Pacheco et al. (2011a) verificaram que a fitomassa remanescente de $P$. glaucum foi insuficiente para proporcionar uma cobertura adequada para a cultura sucessora em plantio direto.

Portanto, o padrão diferenciado da partição de fitomassa da parte aérea entre as espécies de Brachiaria sp. e P. glaucum, possibilita um manejo diferenciado para regiões distintas, uma vez que, as espécies de B.brizantha e B. ruziziensis acumularam $70 \%$ da fitomassa nas folhas, podendo ser mais eficientes na cobertura do solo durante a safra de verão, ao passo, que as espécies de $P$. glaucum acumularam $60 \%$ no caule, podendo contribuir para maior permanência de resíduos vegetais na entressafra. A maior quantidade de fitomassa nas folhas (cobertura do solo) durante a safra de verão permite melhor controle de plantas daninhas (GOULART et al., 2009) enquanto que, a maior permanência de fitomassa na entressafra possibilita maior acúmulo de MO (GARCIA; ROSOLEM, 2010), principalmente em função da menor taxa de decomposição dos resíduos. No entanto, como já abordado anteriormente, apesar da maior permanência dos resíduos de $P$. glaucum no solo e contribuição para o acúmulo de $\mathrm{MO}$, estes são insuficientes para formar uma cobertura uniforme para o SPD.

Independente da espécie avaliada houve decréscimo linear no acúmulo de fitomassa seca total com o aumento do intervalo de turno de rega, (Figura 6B). Todavia, houve diferença no acúmulo de fitomassa entre as espécies, sendo os menores valores verificados para $M$. aterrima, enquanto que, as demais espécies não diferiram entre si. Em condições de disponibilidade de água em torno de $70 \%-80 \%$ da capacidade de campo, que equivale ao turno de rega de dois dias, é possível verificar que os maiores valores de fitomassa seca total foram observados para P. glaucum cv. ADR 7010 e B. ruziziensis (Figura 6B e Tabela 1). Esses resultados assemelham-se aos obtidos por Bonfim-Silva et al. (2011), que verificaram maior produção de fitomassa seca de P. glaucum com umidade em $60 \%$ da capacidade de campo. O melhor desenvolvimento das plantas em 60\% da capacidade de campo, observada no trabalho citado, pode ser atribuída ao solo mais argiloso utilizado no experimento, aumentando a capacidade de armazenamento de água.

Considerando a fitomassa seca total, é possível verificar que $M$. aterrima foi a espécie com maior tolerância aos níveis de déficit hídrico, pois acumulou $40 \%$ da fitomassa seca total no intervalo de turno de rega de oito dias (Tabela 1). Segundo Santos e Campelo Júnior (2003), M. aterrima é uma planta que se destaca pelo seu bom desenvolvimento sob déficit hídrico e altas temperaturas. Mesmo apresentando boa tolerância ao déficit hídrico, essa espécie não superou as demais no acúmulo de fitomassa. Isso se deve principalmente ao lento crescimento inicial observado nos primeiros 30 dias, mesmo na condição de $80 \%$ da capacidade de campo, demonstrando baixa eficiência no uso da água, o que pode ser explicado pelo mecanismo 
$\mathrm{C}_{3}$ de fixação do carbono. Além do mais, por se tratar de uma espécie com metabolismo $\mathrm{C}_{3}$, esta apresenta baixa relação $\mathrm{C} / \mathrm{N}$, resultando em rápida decomposição dos resíduos (OLIVEIRA et al., 2010). Já para $P$. glaucum cv. ADR 7010 e ADR 300 se observou que foi a espécie com menor tolerância ao déficit hídrico, pois acumulou apenas $24 \%$ e $23 \%$ da fitomassa seca total respectivamente no turno de rega de oito dias. No entanto, o rápido crescimento inicial dessas espécies proporcionou os maiores valores de fitomassa seca total aos 65 DAE.

Essa característica, de crescimento inicial rápido é desejável em plantas de cobertura cultivadas na entressafra, pois possibilita o melhor aproveitamento da umidade do solo nos estágios iniciais de desenvolvimento, que nessa época decresce rapidamente.

Houve comportamento semelhante das espécies quanto ao teor relativo de clorofila total (Figura 7). Todavia, apesar das equações de regressão se ajustarem com bons índices de correlação e determinação, apenas as espécies de $B$. brizantha e B. ruziziensis tiveram os teores relativos de clorofila, significativamente influenciadas pelos turnos de rega. Observa-se que as equações apresentaram comportamento quadrático, evidenciando que níveis intermediários de déficit hídrico proporcionaram aumento na leitura do índice de clorofila.

Esses resultados podem ser parcialmente explicados pelo fato de que os medidores portáteis de clorofila determinam os teores relativos e não absolutos de clorofila, ou seja, através da radiação transmitida em três comprimentos de luz através da clorofila, estima-se o índice relativo de clorofila. Acontece que esse índice é determinado por unidade de área foliar, portanto, em condições intermediárias de déficit hídrico há redução na turgescência (potencial hídrico) das células, aumentando o número de células e cloroplastos por unidade de área e consequentemente da radiação absorvida. Já em condições severas de déficit hídrico, como é o caso do turno de rega de oito dias, ocorreu o maior numero de folhas secas, ou seja, as células foram destruídas, e os valores de clorofila decresceram (Figura 7).

Diante disso, os dados das medições indiretas de clorofila (medidores portáteis) em condições de déficit hídrico devem ser tratados com cautela, pois existe a possibilidade de aumento nos teores relativos de clorofila, resultado de aumento da concentração de clorofila por unidade de área avaliada e não por aumento da síntese.

\section{Conclusões}

As espécies de B. brizantha, B. ruziziensis e $P$. glaucum ADR 300 e ADR 7010 destacaram-se na produção de fitomassa da parte aérea e fitomassa e volume do sistema radicular em condições de déficit hídrico.

A espécie $M$. aterrima demonstrou maior tolerância ao déficit hídrico, no entanto, apresentou produção de fitomassa inferior às demais espécies avaliadas.

Independente dos intervalos de turno de rega, as espécies de B. brizantha e B. ruziziensis acumulam maiores quantidades de fitomassa da parte aérea nas folhas, enquanto que o P. glaucum ADR 300 e ADR 7010 acumulam no caule.

Com exceção da fitomassa de folhas secas e teor relativo de clorofila, todos as demais características biométricas são reduzidos com o aumento dos níveis de déficit hídrico.

\section{Referências}

BATJES, N. H. Total carbon and nitrogen in the soils of the world. European Journal of Soil Science, Aberystwyth, v. 47, n. 2, p. 151-163. 1996.

BOER, C. A.; ASSIS, R. L.; SILVA, G. P.; BRAZ, A. J. B. P.; BARROSO, A. L. L.; CARGNELUTTI FILHO, A.; PIRES, F. R. Ciclagem de nutrientes por plantas de cobertura na entressafra em um solo de cerrado. Pesquisa Agropecuária Brasileira, Brasília, v. 42, n. 9, p. 12691276, 2007. 
BONFIM-SILVA, E. M.; SILVA, T. J. A. da; CABRAL, C. E. A.; KROTH, B. E.; REZENDE, D. Desenvolvimento inicial de gramíneas submetidas ao estresse hídrico. Revista Caatinga, Mossoró, v. 24, n. 2, p. 180-186, 2011.

BOUWMANN, A. F.; GERMON, J. C. Introduction: special issue - soils and climate change. Biology and Fertility Soils, Berlin, v. 27, n. 3, p. 219-227, 1998.

CAVALCANTE, I. H. L.; SIVA, R. R. S.; ALBANO, F. G.; LIMA, F. N.; MARQUES, A. S. Foliar Spray of Humic Substances on Seedling Production of Papaya (Pawpaw). Jornal of Agronomy, New York, v. 10, n. 2, p. 118-122, 2011.

CRUSCIOL, C. A. C.; COTTICA, R. L.; LiMA, E. V.; ANDREOTTI, M.; MORO, E.; MARCON, E. Persistência de palhada e liberação de nutrientes do nabo forrageiro no plantio direto. Pesquisa Agropecuária Brasileira, Brasília, v. 40, n. 2, p. 161-168, 2005.

GARCIA, R. A.; ROSOLEM, C. A. Agregados em um Latossolo sob sistema plantio direto e rotação de culturas. Pesquisa Agropecuária Brasileira, Brasília, v. 45, n. 12, p. 1489-1498, 2010.

GIACOMINI, S. J.; AITA, C.; HUBNER, A. P.; LUNKES, A.; GUIDINI, E.; AMARAL, E. B. Liberação de fósforo e potássio durante a decomposição de resíduos culturais em plantio direto. Pesquisa Agropecuária Brasileira, Brasília, v. 38, n. 9, p. 1097-1104, 2003.

GOULART, P.; CAMPOS, S.; BASTIANI, M.; MOREIRA, G.; PEREIRA, L. Desempenho da biomassa das plantas de cobertura de verão na supressão de plantas espontâneas. Revista Brasileira de Agroecologia, Cruz Alta, v. 4, n. 2, p. 3494-3498, 2009.

HEINRICHS, R.; VITTI, G. C.; MOREIRA, A.; FIGUEIREDO, P. A. M.; FANCELLI, A. L.; CORAZZA, E. J. Características químicas de solo e rendimento de fitomassa de adubos verdes e de grãos de milho, decorrente do cultivo consorciado. Revista Brasileira de Ciência do Solo, Viçosa, v. 29, n. 1, p. 71-79, 2005.

MACHADO, P. L. O. de A. Carbono do solo e a mitigação da mudança climática global. Química Nova, São Paulo, v. 28, n. 2, p. 329-334, 2005.

MOREIRA, J. A. A.; AGUIAR, R. A.; STONE, L. F.; BERNARDES, T. G.; PEREIRA FILHO, I. A.; CRUZ, J. C. Efeito de diferentes plantas de cobertura do solo sobre alguns atributos do solo em sistema de produção orgânico. Revista Brasileira de Agroecologia, Cruz Alta, v. 4, n. 2, p. 3748-3751, 2009.
OLIVEIRA, F. L.; GOSCH, C. I. L.; GOSCH, M. S.; MASSAD, M. D. Produção de fitomassa, acúmulo de nutrientes e decomposição de leguminosas utilizadas para adubação verde. Revista Brasileira de Ciências Agrárias, Recife, v. 5, n. 4, p. 503-508, 2010.

PACHECO, L. P.; BARBOSA, J. M.; LEANDRO, W. M.; MACHADO, P. O. de A.; ASSIS, R. L. de; MADARI, B. E.; PETTER, F. A. Produção e ciclagem de nutrientes por plantas de cobertura nas culturas de arroz de terras altas e de soja. Revista Brasileira de Ciência do Solo, Viçosa, v. 35, n. 6, p. 1787-1799, 2011 b.

PACHECO, L. P.; LEANDRO, W. M.; MACHADO, P. O. de A.; ASSIS, R. L. de; COBUCCI, T.; MADARI, B. E.; PETTER, F. A. Produção de fitomassa e acúmulo e liberação de nutrientes por plantas de cobertura na safrinha. Pesquisa Agropecuária Brasileira, Brasília, v. 46, n. 1, p. 17-25, 2011a.

PACHECO, L. P.; PETTER, F. A. Benefits of cover crops in soybean plantation in Brazilian cerrados. In: TZI BUN, N. G. Soybean: applications and technology. Rijeka: InTech, 2011. p. 67-94.

PACHECO, L. P.; PIRES, F. R.; MONTEIRO, F. P.; PROCOPIO, S. O.; ASSIS, R. L.; CARMO, M. L.; PETTER, F. A. Desempenho de plantas de cobertura em sobressemeadura na cultura da soja. Pesquisa Agropecuária Brasileira, Brasília, v. 43, n. 7, p. 815-823, 2008.

PETTER, F. A.; MADARI, B. E. Biochar: agronomic and environmental potential in Brazilian savannah soils. Revista Brasileira de Engenharia Agrícola e Ambiental, Campina Grande, v. 16, n. 7, p. 761-768, 2012.

PORTES, T. A.; CARVALHO, S. I. C.; OLIVEIRA, I. P.; KLUTHCOUSKI, J. Análise do crescimento de uma cultivar de braquiária em cultivo solteiro e consorciado com cereais. Pesquisa Agropecuária Brasileira, Brasília, v. 35, n. 7, p. 1349-1358, 2000.

PRIOR, S. A.; TORBERT, H. A.; RUNION, G. B.; ROGERS, H. Elevated atmospheric $\mathrm{CO}_{2}$ in agroecosystems: residue decomposition in the field. Environmental Management, Berlin, v. 33, p. 344-354, 2004. Supplement 1.

SANTOS, V. S.; CAMPELO JÚNIOR, J. H. Influência de elementos meteorológicos na produção de adubos verdes, em diferentes épocas de semeadura. Revista Brasileira de Engenharia Agrícola e Ambiental, Campina Grande, v. 7, n. 1, p. 91-98, 2003. 
SILVA, M. B.; KLIEMANN, H. J.; SILVEIRA, P. M.; LANNA, A. C. Atributos biológicos do solo sob influência da cobertura vegetal e do sistema de manejo. Pesquisa Agropecuária Brasileira, Brasília, v. 42, n. 1, p. 1-7, 2007.

SODRÉ FILHO, J.; CARDOSO, A. N.; CARMORAL, R.; CARVALHO, A. M. Fitomassa e cobertura do solo de culturas de sucessão ao milho na Região do Cerrado. Pesquisa Agropecuária Brasileira, Brasília, v. 39, n. 4, p. 327-334, 2004.

SUZUKI, L. E. A. S.; ALVES, M. C.; SUZUKI, L. G. A. S.; RODRIGUES, R. A. F. Fitomassa de plantas de cobertura sob diferentes sistemas de cultivo e sucessão de culturas em Selvíria - MS. Científica, Joboticabal, v. 36, n. 2, p. 123-129, 2008.

TAIZ, L.; ZEIGER, E. Fisiologia vegetal. 4. ed. Porto Alegre: Artmed, 2009. 819 p.
TIMOSSI, P. C.; DURIGAN, J. C.; LEITE, G. J. Formação de palhada por braquiárias para adoção do sistema plantio direto. Bragantia, Campinas, v. 66, n. 4, p. 617-622, 2007.

TORRES, J. L. R.; PEREIRA, M. G. Dinâmica do potássio nos resíduos vegetais de plantas de cobertura no cerrado. Revista Brasileira de Ciência do Solo, Viçosa, v. 32, n. 4, p. 1609-1618, 2008.

TORRES, J. L. R.; PEREIRA, M. G.; ANDRIOLI, I.; POLIDORO, J. C.; FABIAN, A. J. Decomposição e liberação de nitrogênio de resíduos culturais de plantas de cobertura em um solo de cerrado. Revista Brasileira de Ciência do Solo, Viçosa, v. 29, n. 4, p. 609-618, 2005.

TORRES, J. L. R.; PEREIRA, M. G.; FABIAN, A. J. Produção de fitomassa por plantas de cobertura e mineralização de seus resíduos em plantio direto. Pesquisa Agropecuária Brasileira, Brasília, v. 43, n. 3, p. 421-428, 2008. 
